\title{
RELATOS DE EXPERIENCIA

\section{Em busca de uma iniciativa histórica africana: possibilidades e limites das práticas pedagógicas na educação básica}

Débora Cristina de Araujo ${ }^{\mathrm{I}, \text { II }}$

http://dx.doi.org/10.24109/2176-6681.rbep.99i252.3577

\section{Resumo}

Este artigo apresenta um conjunto de atividades desenvolvidas em turmas de $6^{\circ}$ ano do ensino fundamental durante as aulas de língua portuguesa, com a proposta de promover rupturas epistemológicas na compreensão das crianças sobre cultura, estética e história africanas. Para tanto, utiliza como referenciais analíticos as produções das crianças, além de uma revisão teórica do campo das práticas pedagógicas e dos marcos legais que fundamentam a educação das relações étnico-raciais no Brasil.

Universidade Federal do Espírito Santo (UFES). Vitória, Espírito Santo, Brasil. E-mail: $<$ debbora.a@hotmail.com>; $<$ https://orcid.org/0000-00 01-8442-3366>

II Doutora em Educação pela Universidade Federal do Paraná (UFPR). Curitiba, Paraná, Brasil. As modificações curriculares (ainda em curso) demandadas pela aprovação de um conjunto de leis, resoluções e diretrizes que fomentam o ensino de história e cultura afro-brasileira e africana na educação brasileira têm sido produzidas em campos de tensões, negociações e muitas vezes rupturas epistêmicas. Soma-se a forte tendência de conteúdos e práticas pedagógicas eurocêntricos, influenciados por um padrão de poder que emergiu como resultado do colonialismo moderno, a colonialidade. O que as práticas 
aqui descritas revelaram é que os limites ainda são muitos diante da força da colonialidade. O desafio que se apresenta à escola é, portanto, pensar outras possibilidades pedagógicas para subverter tal colonialidade e avançar na construção de um ensino fundamentado no reconhecimento de que a produção intelectual, política, cultural e social africana e afro-brasileira é necessária à formação escolar da população brasileira.

Palavras-chave: cultura afro-brasileira; colonialismo; práticas educativas.

\section{Abstract \\ Searching for an African historical initiative: possibilities and limitations of the pedagogical practices in basic education}

This paper presents a series of activities carried in sixth-grade Portuguese classes, aimed to facilitate epistemological ruptures in the children's understanding of the African culture, aesthetics, and history. To do so, the study uses as analytical references the children's productions, a theoretical review in the field of teaching practices, and the legal milestones that underpin the ethnic-racial relations education in Brazil. The (still ongoing) curricular amendments, required through the passing of a set laws, resolutions, and guidelines that promote the teaching of African and Afro-Brazilian history and culture in the Brazilian education system, have been brought up amidst tensions, negotiations and often epistemic ruptures. The strong trend towards Eurocentric pedagogical content and practices are gathered, influenced by a power pattern that emerged out of modern colonialism, the coloniality. Furthermore, the practices herein uncover the fact that there are still too many limitations when compared to the power of coloniality. Therefore, the school faces the challenge of imagining new pedagogical outcomes to subvert the aforementioned coloniality and push towards the development an education grounded on the acknowledgment that the African and Afro-Brazilian intellectual, political, cultural and social production is fundamental to the education of the Brazilian population.

Keywords: Afro-Brazilian culture; colonialism; educational practices.

\section{Introdução}

Então, é assim que se cria uma única história: mostre um povo como uma coisa, como somente uma coisa, repetidamente, e será o que eles se tornarão. [...] 
A única história cria estereótipos. E o problema com os estereótipos não é que eles sejam mentira, mas que eles sejam incompletos. Eles fazem uma história tornar-se a única história.

Chimamanda Adichie (2009)

O ensino de história e cultura africana e afro-brasileira foi, sobretudo durante o século 20, uma das mais importantes demandas do movimento negro no Brasil. A mobilização em torno da agenda educacional como forma de enfrentamento ao racismo conseguiu impulsionar - a despeito dos limites, conforme serão discutidos adiante - importantes pautas nas políticas educacionais no País. Essas e outras pautas têm produzido uma série de debates e análises críticas sobre epistemologias, formação docente e, sobretudo, currículo. São novas configurações que, produzidas sob a égide da luta por direitos, passam a questionar as vozes hegemônicas que se manifestam no currículo e que corporificam, conforme aponta Silva (1995, p. 195), "noções particulares sobre conhecimento, sobre formas de organização da sociedade, sobre os diferentes grupos sociais".

À medida que a tensão aumenta, importantes transformações ocorrem, pois, concordando com Gomes (2012a, p. 99), o conflito passa a ocupar "o centro de toda experiência pedagógica emancipatória", tornando vulnerável e desestabilizando "os modelos epistemológicos dominantes". Assim, as demandas propostas pelo conjunto de documentos que fundamentam os princípios da educação das relações raciais (Lei no 10.639/2003, Diretrizes Curriculares Nacionais para a Educação das Relações Étnico-Raciais e para o Ensino de História e Cultura Afro-Brasileira e Africana, Lei no 11.645/2008, e outros) têm, mesmo que aquém do almejado, mobilizado transformações na educação. E, por sua vez, as transformações em curso têm acionado novas reflexões sobre os alcances de uma legislação tão pujante e, ao mesmo tempo, ainda em processo de implementação, demonstrando que, como é inerente à dinâmica da sociedade, nenhuma política educacional atua de modo similar e, muito menos, repercute em resultados homogêneos, ainda mais se embrenhada de resistências e, principalmente, do racismo institucionalizado.

Assim, este artigo propõe, em um período relativa e suficientemente posterior às primeiras mudanças na legislação educacional brasileira (que ocorreram em 2003 e 2004), apresentar as potencialidades e os limites das práticas pedagógicas que buscam promover reflexões e compreensões críticas acerca da cultura, estética e história africanas. Antes, no entanto, a legislação que fundamenta a educação das relações étnicoraciais (ERER) $)^{1}$ será brevemente revisada com vistas à avaliação de seu alcance na contemporaneidade. Em seguida, será proposta uma reflexão particular sobre a colonialidade e o eurocentrismo que marcam a educação

A partir daqui, no decorre deste texto, será utilizada a sigla ERER para se referir à educação das relações étnico-raciais. brasileira e atuam de modo a enfraquecer as iniciativas de retomada de um protagonismo dos conhecimentos africanos e afro-brasileiros na educação nacional. Posteriormente a tal contextualização, serão apresentados os 
resultados de uma série de atividades desenvolvidas em aulas de língua portuguesa de turmas de $6^{\circ}$ ano, no período de um ano letivo.

O que se pretende com este texto é refletir sobre os passos seguintes a serem trilhados para que a educação das relações étnico-raciais não seja mais um acumulado de leis que rememoram, no ambiente escolar, o mero cumprimento legal "no papel", e passe a representar ações e práticas pedagógicas fundamentadas em bases teóricas emancipatórias e críticas, no tocante à história e cultura de povos historicamente inferiorizados ou invisibilizados na dimensão dos conhecimentos escolares.

\section{Reflexões sobre a atuação do racismo institucional nos marcos legais da educação das relações étnico-raciais}

Com o passar dos anos e com a difusão de debates no interior das escolas - por força de lei; por iniciativas individuais ou de coletivos de professoras e professores; ou pela atuação de entidades do movimento negro -, é bastante comum o entendimento de que as modificações ocorridas na Lei de Diretrizes e Bases da Educação (LDB), em seus artigos 26A e 79B, por meio das Leis $\mathrm{n}^{\circ}$ 10.639/2003 e $\mathrm{n}^{\circ}$ 11.645/2008, devem estimular mudanças nas práticas pedagógicas nos ambientes escolares. Mas nem todo o sistema educacional brasileiro compreendeu ainda qual a importância de modificações que tornaram obrigatório o ensino de história e cultura afro-brasileira, africana e indígena. Acrescenta-se o fato do quase total desconhecimento de outros documentos produzidos no âmbito educacional, como as Diretrizes Curriculares Nacionais para a Educação das Relações Étnico-Raciais e para o Ensino de História e Cultura Afro-Brasileira e Africana ou as Diretrizes Curriculares Nacionais para a Educação Escolar Indígena, ambas aprovadas por pareceres do Conselho Nacional de Educação (Parecer CNE/CP n 3/2004 e Parecer CNE/CEB no 13/2012). Reiteram-se, ainda, outras dificuldades:

- a ênfase da Lei no 10.639/2003 nas três áreas do conhecimento, gerando, mais em períodos próximos a sua aprovação e menos atualmente, o entendimento equivocado de que apenas as disciplinas lá citadas ("Educação Artística, Literatura e História") deveriam sofrer modificações;

- a aprovação da Lei $n^{0} 11.645 / 2008$, que incluiu na LDB a obrigatoriedade do ensino de história e cultura indígenas e foi aprovada sem o embasamento teórico necessário, classificando em sua redação a população negra e a população indígena brasileira como "dois grupos étnicos"; além disso, evidenciou-se a pouca influência e participação de movimentos indígenas na elaboração de tal documento.

Somados a tais fatores, os poucos investimentos financeiros e humanos na produção de políticas públicas em âmbitos locais e nacionais que 
promovam cursos de formação docente em nível inicial e complementar, bem como a pouca acessibilidade a materiais teórico-metodológicos e, sobretudo, o baixo investimento simbólico no combate ao racismo atribuem ao contexto a ideia de oscilação entre implementação e implantação. Gomes (2012b, p. 26) analisa que tal situação ocorre principalmente pela impossibilidade de uma "passagem estanque e linear entre a implantação e a implementação" que, embora seja inerente a toda política pública, intensifica-se no caso da ERER devido a manifestações de resistências e refutação das novas propostas educacionais (chamadas posteriormente neste texto como marcas do racismo institucional). Assim, os estágios de implementação e implantação ocorrem concomitantemente na educação brasileira e à "medida que se apresentam as tensões da implantação, se estabelece um conjunto de ações articuladas para a implementação, em resposta aos problemas identificados" (Gomes, 2012b, p. 27).

$\mathrm{E}$ quais são os fatores que inviabilizam a passagem de modo mais eficiente da implantação (correspondente à fase inicial de construção de uma política) à implementação ou internalização dos princípios que regem a política? Deve-se, sobretudo, ao fato de que, apesar da demarcação legal, o racismo institucional tem impedido o reconhecimento de que a produção intelectual, cultural e social africana exerceu/exerce forte impacto na sociedade brasileira e em suas formas de organização.

O conceito de racismo institucional ganhou força no Brasil a partir da "Marcha Zumbi Contra o Racismo, pela Cidadania e a Vida", organizada por entidades do movimento negro, que levou a Brasília milhares de pessoas de todo o País. Por meio de tal evento, realizado em 20 de novembro de 1995 , entidades representativas entregaram um documento ao então presidente da República Fernando Henrique Cardoso, indicando as reivindicações na luta de combate ao racismo e superação das desigualdades raciais. Mas foi nos anos 2000 que se consolidou a discussão entre entidades do movimento negro e o governo brasileiro, sobretudo a partir da $3^{a}$ Conferência Mundial das Nações Unidas contra o Racismo, a Discriminação Racial, a Xenofobia e as Formas Conexas de Intolerância, realizada em Durban, na África do Sul, em 2001. Intensificaram-se as reivindicações de efetivação dos compromissos firmados pelo Brasil nessa conferência por ter se mobilizado um debate público sobre a questão racial e atuação do poder público ao mesmo tempo, o que proporcionou trocas de experiências desenvolvidas em outros países.

Em decorrência desse momento histórico, em 2005 foi implementado pelo governo brasileiro o Programa de Combate ao Racismo Institucional (PCRI), com foco no combate ao racismo na área da saúde. É o estudo de Laura Cecilia López que nos apresenta tal definição, considerando a dificuldade de acessar tal documento em sua versão original:

O racismo institucional é o fracasso das instituições e organizações em prover um serviço profissional e adequado às pessoas em virtude de sua cor, cultura, origem racial ou étnica. Ele se manifesta em normas, práticas e comportamentos discriminatórios adotados no cotidiano do 
trabalho, os quais são resultantes do preconceito racial, uma atitude que combina estereótipos racistas, falta de atenção e ignorância.

Em qualquer caso, o racismo institucional sempre coloca pessoas de grupos raciais ou étnicos discriminados em situação de desvantagem no acesso a benefícios gerados pelo Estado e por demais instituições e organizações. (CRI, 2006, p. 22 apud López, 2012, p. 128).

Evidencia-se que o racismo institucional é potencializado se comparado com manifestações de racismo produzidas individualmente ou por pequenos grupos, já que ele se configura em práticas institucionalizadas de poder. Assim, o racismo exercitado por instituições pode ter consequências amplas para um contingente maior de pessoas do que o racismo exercido no plano individual. Teun Van Dijk, ao discutir sobre o racismo contemporâneo, incluindo o discurso racista, ressalta a importância de considerarmos a influência das elites nesse contexto, já que elites "políticas, burocráticas, corporativas, jornalísticas, educacionais e acadêmicas controlam as mais cruciais dimensões e decisões da vida cotidiana de imigrantes e minorias: entrada, residência, trabalho, [...] conhecimento, informação e cultura" (Van Dijk, 2008, p. 133). A produção dos discursos por parte desses grupos pode representar "uma importante forma de racismo da elite" (Van Dijk, 2008, p. 134). Renísia Filice, em investigação do processo de implementação do artigo 26A da LDB (Lei $\mathrm{n}^{\circ}$ 10.639/2003), identificou a estratégia de "desarticulação aparente entre políticas econômicas e políticas sociais", em que "as políticas econômicas assumem a primazia em todo o planejamento governamental, cabendo às políticas sociais um papel secundário" (Filice, 2010, p. vi). Além disso, por meio das visões de mundo e das convicções de gestoras e gestores investigados, emergiram "práticas racistas imbricadas no imaginário coletivo [...], pondo-nos frente a frente com o lado atroz da cultura nacional, a cultura do racismo, que atravessa a sociabilidade brasileira" (Filice, 2010, p. vi).

É válida, portanto, a interpretação de que o racismo institucional se renova e se revela multifacetado, sendo responsável pela corrosão de políticas públicas e pela desmotivação de transformações na sociedade por se constituir de supostos equívocos e desorganizações no repasse de informações, ou apenas silêncio. No ambiente escolar, aliados a tal institucionalidade estão os princípios eurocêntricos, consolidados na estrutura da escola, dos currículos e das práticas pedagógicas.

\section{A influência da colonialidade e do eurocentrismo nas práticas pedagógicas}

Ao enfatizar a força do racismo institucionalizado, não cabe somente caracterizá-lo, mas também vinculá-lo às suas bases. E, na interpretação aqui proposta, o racismo institucionalizado nada mais é do que uma das consequências da colonialidade, um padrão de poder emergente do colonialismo moderno, mas que, como argumenta Nelson Maldonado 
Torres, adquiriu maior influência e poder por ter superado o colonialismo. Colonialidade relaciona-se "à forma como o trabalho, o conhecimento, a autoridade e as relações intersubjetivas articulam-se entre si através do mercado capitalista mundial e da ideia de raça" (Maldonado Torres, 2007, p. 131).

Ela se mantém viva em textos didáticos, nos critérios para o bom trabalho acadêmico, na cultura, no sentido comum, na autoimagem dos povos, nas aspirações dos sujeitos e em muitos outros aspectos de nossa experiência moderna. Neste sentido, respiramos a colonialidade na modernidade cotidianamente. (Maldonado Torres, 2007, p. 131).

Antes da definição de colonialidade, outro conceito permeava os estudos sobre o racismo e suas consequências a partir da colonização: trata-se do eurocentrismo, que é relevante ainda nas interpretações contemporâneas da educação por evidenciar que, além de colonizado, o currículo é também eurocêntrico.

O etnocentrismo é uma característica presente em qualquer grupo humano, por relacionar-se diretamente com o desejo de valorização e autoproteção dos atributos de uma sociedade, o qual não pode ser identificado no eurocentrismo, uma forma particular de etnocentrismo que ignora a capacidade de autopreservação da imagem de outros grupos humanos, restringindo e reduzindo qualquer produção de saber, conhecimento e de humanidade à Europa (mesmo que todo esse continente não fosse diretamente associado a tal ideia, mas sobretudo à Europa Ocidental). Consequentemente, outros conceitos caros à contemporaneidade, como a ideia de modernidade e racionalidade, foram imaginados, conforme argumenta Quijano (2005, p. 122), "como experiências e produtos exclusivamente europeus". Disso derivaram categorias responsáveis por explicar a estruturação do resto do mundo diante da Europa: "OrienteOcidente, primitivo-civilizado, mágico/mítico-científico, irracional-racional, tradicional-moderno" (Quijano, 2005, p. 122).

Conduzindo esse contexto interpretativo para o ambiente escolar, é possível caracterizar que uma das mais dilacerantes consequências do eurocentrismo é, portanto, o desenvolvimento de uma falsa consciência de superioridade ou de inferioridade intelectual e cultural, corporificada na escola por meio da distribuição desigual de conteúdos relacionados à produção de conhecimentos do "resto do mundo" e da Europa. Por efeito, o reforço de preconceitos e estereótipos negativos se naturaliza como prática de esvaziamento de diferentes perspectivas e paradigmas produzidos pelos "outros". A ideia de raça soma-se ao eurocentrismo, legitimando, sobretudo no contexto das Américas, as relações de dominação impostas pela conquista. Assim, raça converteu-se em um importante e pioneiro critério de classificação dos povos do mundo em "níveis, lugares e papéis na estrutura de poder da nova sociedade. Em outras palavras, no modo básico de classificação social universal da população mundial" (Quijano, 2005, p. 118). 
Em pesquisa em escola pública no início da década de 1990, Gomes (1996) identificou características pelas quais o eurocentrismo e a colonialidade operavam. Tais características foram, no presente artigo, transformadas em categorias, as quais serão analisadas a seguir tomando outros breves exemplos de pesquisas acadêmicas que, mesmo posteriormente ao período pesquisado por Gomes, captaram as mesmas práticas.

\section{Incapacidade intelectual do negro}

Para Gomes (1996), a recorrência de práticas que subestimam a capacidade intelectual de estudantes negros (em detrimento de capacidades físicas) remonta a interpretações do racismo científico. E, embora tal perspectiva tenha sido fortemente combatida a partir do holocausto europeu, no senso comum, no ambiente escolar e na interpretação sobre avaliação e desempenho escolar/acadêmico, está ainda presente.

Um exemplo foi captado por Denise Ziviani em uma escola pública localizada em um aglomerado de favelas em Belo Horizonte. Em sua investigação com professoras alfabetizadoras, a autora identificou que, entre os processos de desqualificação da escola e dos sujeitos por ela formados, estava a classificação de estudantes entre "fracos" e aqueles "que são mais fracos ainda". É o que argumentou uma das professoras: "[...] então a Rafaela do oi azul [...] ela tem mais facilidade... tem muito conhecimento assim... em relação... muito maior... bem mais desenvolvido que os outros... mas aí... cê sabe né? [...]" (Ziviani, 2012, p. 104).

Outra pesquisa, de Leticia Passos de Melo Sarzedas, analisou depoimentos de crianças e professoras acerca da "visão que se tem da criança negra no espaço escolar" (Sarzedas, 2007, p. v). Em determinado depoimento, uma das professoras da escola, ao justificar as diferenças entre estudantes negros e não negros, nega que seja de ordem racial, mas seu discurso releva o contrário:

\footnotetext{
Por mais que seja correto falar que todo mundo é igual, eu acho que não é bem assim, não. Eu vejo que meus alunos negros são mais agitados, mais sem-educação. Acho que isso é de família. Não sei por que isso acontece. Acho que vem de casa, sabe. [...] Eu preciso ver que eles são diferentes, senão vou ficar fingindo. Não que eu ache que seja pela cor, não. Mas que eles são diferentes, eles são. Só não consigo entender o porquê [...]. (Ana Luisa). (Sarzedas, 2007, p. 112).
}

Para Gomes (1996), em manifestações que evidenciam, com base no critério racial, uma baixa expectativa em relação ao desempenho intelectual de um estudante negro ou, de outro lado, quando se mostram altamente admirados pelo bom desempenho, reificam-se as teorias do racismo científico do século 19. 


\section{Ideologia do branqueamento}

Outra categoria presente no ambiente escolar identificada por Gomes se refere à tentativa de suavizar o pertencimento racial dos estudantes "apelando para as nuances de cor como moreninho, chocolate, marronzinho, cor de jambo, ou até mesmo em expressões como 'clarear a raça'" (Gomes, 1996, p. 70-71).

Eliane Cavalleiro desenvolveu, no final da década de 1990, em uma escola municipal de educação infantil de São Paulo, "o acompanhamento do indivíduo no convívio social, em suas relações multiétnicas, como as pensa e as elabora". (Cavalleiro, 2006, p. 12). Embora a passagem seguinte revele um exemplo vivenciado pela própria autora no contexto de pesquisa, demonstra essa constante tendência de suavização da cor e dos traços negros: "No final de uma entrevista com uma professora negra, ela comentou: 'Você é muito bonita. Não seria discriminada. Hoje o negro está mais bonito. Você passa por branca. Ninguém te discrimina'" (Cavalleiro, 2006, p. 41).

Sarzedas (2007) apresenta outro exemplo que ratifica o quanto a ideologia do branqueamento impacta agressivamente na formação identitária das crianças e dos adolescentes, sobretudo negros:

As crianças estão divididas em grupos. Em um dos grupos estão Débora, Marina, João e Patrícia. As crianças estão colorindo suas figuras enquanto conversavam:

- Que cor eu pinto a menina, tia? Pergunta Patrícia.

- De cor da pele, ué!? Responde Paula [a professora].

- Então eu vou pintar meu menino de marrom.

- Credo... parece sujeira! Comenta Débora.

João pergunta:

- E você é de que cor, menina?

- Suja. Responde Débora.

Todas as crianças do grupo riem do comentário.

As crianças continuam pintando, enquanto Débora relata:

- Eu ganhei uma boneca preta da minha tia.

João comenta:

- Credo... que feio!

Débora completa:

- Eu queria jogar no lixo, mas minha mãe falou que vai tentar lavar com QBoa pra ver se ela fica branca. Eu vou pintar minha boneca bem linda... loira.

A professora, Paula, acompanha a conversa sem nenhum comentário. (Sarzedas, 2007, p. 111).

Também na pesquisa de Ziviani (2012), interpretações de professoras apresentam limites sobre a importante e necessária discussão a respeito do fortalecimento da identidade de crianças negras:

Professora Isabel: O que eu não entendo é por que eles, os alunos, têm preconceito com o negro, se eles são negros?

Professora Helena: Isso é uma forma de resistência. Você tinha que ver os meninos da manhã, da sala-projeto. Quando eu perguntei quem era negro, ninguém levantou a mão... são morenos. Fazem isso pra se proteger, porque já são muito discriminados. (Ziviani, 2012, p. 203). 
Embora tal interpretação seja uma parte do problema, ela não corresponde à totalidade por não investigar os motivos que levam à negativa dos meninos em se assumirem negros. Nesse caso, a ideologia do branqueamento já foi internalizada e incorporada às suas identidades.

Para Gomes (1996), essa teoria imiscuída no ambiente escolar é, também, herança de teorias científicas que pretendiam embranquecer o Brasil como forma de superação da sua influência africana expressa visivelmente entre a população do País.

\section{Primitividade da cultura negra}

Outra estratégia recorrente da manifestação do racismo no ambiente escolar se atrela diretamente à força do eurocentrismo no currículo. Ao não ter estruturados e sistematizados os conhecimentos sobre a produção e a história africanas, as tentativas de inserção de tais práticas muitas vezes recaem em estereótipos altamente negativos.

Ainda assistimos às festas escolares, principalmente na comemoração do dia do folclore, números em que os/as alunos/as representam a contribuição das "três raças formadoras", enfatizando a cultura europeia como a matriz e a índia e a negra como meros adendos, ou seja, algumas "contribuições" nos costumes, no vestuário, nas crenças. Nega-se, portanto, a riqueza de processos sócio-culturais tão importantes e que são constituintes da formação da sociedade brasileira. (Gomes, 1996, p. 71).

Nas pesquisas aqui citadas, tais práticas se mostraram recorrentes. Cavalleiro relata um caso muito próximo do exemplo de Gomes:

Engraçado que sempre vem essa história de cor. E agosto é uma ótima época para se falar disso porque a gente tem o saci-pererê, a gente tem mula-sem-cabeça, tem índio. E é a época do folclore, e é uma festa. Você aproveita uma data que é muito mágica e transforma isso. Você meio que desbanca a molecada. (Idalina). (Cavalleiro, 2006, p. 71).

De modo semelhante, Sarzedas (2007) captou um diálogo entre professoras: "A gente pode aproveitar as comemorações, usar o folclore, o Zumbi. Assim eles teriam uma boa imagem da África e dos negros. (Rebeca)" (Sarzedas, 2007, p. 105).

\section{Democracia racial}

Além da ideia de que as "três raças" constituem a nação brasileira, qualquer prática discriminatória, ou consequências/sequelas de discriminação, é atribuída à questão de ordem econômica, o que nega o racismo estruturado em nossa sociedade. A pesquisa de Sarzedas apresenta os exemplos mais "incisivos" de interpretações de professoras: 
A Lei Áurea foi assinada. O negro já é livre e, portanto, somos todos iguais, com oportunidades iguais. Se o negro ainda se encontra pobre, é por outros motivos que não a escravidão e o racismo. (Paula)

$[\ldots]$

Tudo agora é racismo., Muitos negros estão desse jeito por causa de seu próprio preconceito. E fácil dizer que a culpa é dos brancos. Eles (os negros) não veem que estão na pobreza porque assim quiseram. [...] Não é por culpa do racismo, não. Eles que não querem mudar. (Anita)

$[\ldots]$

Eu concordo. O negro no Brasil sempre foi bem tratado. Até na época da escravidão! Ele não passava fome, pois era caro. Depois ficou melhor ainda. Aqui todo mundo tem as mesmas oportunidades. Se existe preconceito e diferença de oportunidades é entre quem é rico e quem é pobre. Independente de ser preto ou branco. [...] Aqui preto casa com branco, tem filho mulato... Isso é discriminação? (Paula). (Sarzedas, 2007, p. 101-102).

Com tais categorias e os exemplos de pesquisas brevemente apresentados, ratifica-se a compreensão de que teorias racistas, baseadas em pressupostos eurocêntricos balizados pela colonialidade, são diariamente reproduzidas no ambiente escolar. No entanto, algumas estratégias de subversão têm sido estimuladas e desenvolvidas no contexto educacional. Um desses exemplos será explorado na seção seguinte.

\section{Rupturas epistemológicas e retomada da iniciativa histórica: um desafio necessário}

Um primeiro elemento a ser considerado no sentido de enfrentar e enfraquecer práticas pedagógicas reificadoras de subalternidade da cultura, da história e dos conhecimentos africanos e afro-brasileiros é fomentar o conflito, na perspectiva pedagógica. Nas palavras de Boaventura Sousa Santos, a ideia de conflito é mobilizada na chave da educação, "pois, para o inconformismo, para um tipo de subjetividade que submete a uma hermenêutica de suspeita a repetição do presente, que recusa a trivialização do sofrimento e da opressão e veja neles o resultado de indesculpáveis opções" (Santos, 1996, p. 17). Ao acionar, na prática pedagógica e, por extensão, nos estudantes, a capacidade de questionamento de verdades antes absolutas e agora refutáveis, antes hegemônicas e agora deslegitimadas, dá-se o primeiro passo no sentido de desestabilizar as bases do eurocentrismo na educação.

Gomes (2012a) propõe que esse processo pode ocorrer por intermédio de rupturas epistemológicas e curriculares, responsáveis por deslocar conteúdos, conceitos e conhecimentos à margem da educação para o centro e intensificar o ato de tornar "público e legítimo o 'falar' sobre a questão afro-brasileira e africana" (Gomes, 2012a, p. 105). Com base em tal perspectiva, serão exemplificadas a seguir práticas pedagógicas que buscaram essa tensão por meio de rupturas epistemológicas. 
Em duas turmas de $6^{\circ}$ ano de um colégio público da região metropolitana de Curitiba, foi possível realizar um trabalho de conflito para a ruptura. Ao longo do ano letivo de 2015, as ações desenvolvidas fomentaram coletivamente intensas reflexões acerca de diversos conteúdos marginalizados no currículo e não somente relacionados à educação das relações étnico-raciais. Foram desenvolvidas, por exemplo, a temática da violência sexual contra crianças e adolescentes, sobretudo com base em relatos de assédios de meninos da escola contra algumas meninas; houve reflexões sobre a representação dos modelos de família convencional e as novas configurações de família (articuladas, obviamente, ao tema da homofobia, transfobia, lesbofobia e misoginia); foram debatidas as compreensões equivocadas a respeito das religiões de matrizes africanas e a espiritualidade indígena e estereótipos que rodeiam o imaginário das crianças acerca dos povos indígenas. Mas é no que se refere à cultura e história afro-brasileira e africana que neste texto serão apresentados mais detalhadamente os resultados.

O grande desafio apresentado à estratégia do conflito é o que repor no "lugar ausente", o que inserir no lugar daquele conhecimento escolar e social adquirido que estabelecia como verdade a ideia de superioridade racial, intelectual e cultural europeia. O caminho se revelou mais complexo do que se supunha durante as práticas pedagógicas, pois era necessário propor a mudança de olhar para que o "exótico" e o "estranho" passassem a ser vistos como representações do desconhecido ao limitado olhar ocidental. Afinal, como bem caracterizou Césaire (2011, p. 269): "A colonização é esse fenômeno que inclui, entre outras consequências psicológicas, a seguinte: fazer vacilar os conceitos sobre os quais os colonizados poderiam construir ou reconstruir o mundo".

Depois de investigar as interpretações recorrentes das turmas sobre a África e sua população, ${ }^{2}$ o passo seguinte foi apresentar elementos do continente africano e seus povos, com exemplos acerca da produção tecnológica, intelectual, artística, estética, entre outras. Mas ainda prevalecia pouca adesão àquelas informações, para muitas crianças inéditas até então. Acrescia-se o fato de que, ao ser exposta às turmas uma variedade de fotografias de pessoas africanas, ou africanas da diáspora, com base em catálogos de moda, ${ }^{3}$ e apresentadas com vestimentas e adornos diversos e heterogêneos entre si, nas reações das crianças ainda prevalecia a comparação com o modelo humano branco e o rechaço daquelas imagens que viam, sobretudo em relação à combinação cor de pele e cabelo. Essas manifestações foram temas de amplos debates nas turmas quando indagados sobre os motivos de alguns terem declarado "feio", "horrível", "ridículo", enquanto outros estudantes contra-argumentavam.

Com os debates, as reflexões se enveredaram para a interpretação de que talvez aquelas representações fossem estranhas aos nossos olhos ocidentais porque fomos acostumados a reconhecer como belo somente o que é branco (a exemplo da televisão, da literatura etc.). Assim, com algumas dúvidas sobre as verdades antes absolutas, foi estimulada outra reflexão: as histórias individuais. Com base em interpretações diversas acerca da obra

\footnotetext{
2 Devido às dimensões deste texto, esse procedimento não será detalhado. Em síntese, a proposta versava sobre uma série de ideias e conceitos que as crianças nutriam acerca do continente africano. $\mathrm{E}$ as respostas, ainda que com ressalvas significativas, foram as "convencionais": miséria, aids, animais selvagens, dança, entre outros.

3 É preciso ressaltar que a escolha das imagens levou em conta aspectos muitas vezes ignorados pelos padrões ocidentais de beleza, como faixa etária (desde crianças a idosos); tipo físico (pessoas magras e gordas); variedade de vestimentas (tradicionais e contemporâneas); diversidade de estilos; variedade de tonalidades de pele e de cabelo.
} 
literária Cada um com seu jeito, cada jeito é de um!, de Lucimar Rosa Dias (2012), a proposta foi buscar, na história e na cultura de cada estudante, elementos que corroboravam a ideia de que a presença africana demarcava suas trajetórias individuais e familiares. Para tanto, foi disponibilizado, em sala de aula, um espelho grande (de $90 \times 30 \mathrm{~cm}$ ) para que cada criança pudesse olhar para si e buscar alguma(s) característica(s) física(s) ou histórica(s) - pois o olhar no espelho implicava também olhar para a história de seus antepassados conhecidos e desconhecidos - relacionada(s) a sua ancestralidade africana, considerando que naquele momento já haviam compreendido que todo ser humano originou-se do continente africano e, nos continentes europeu e americano, a presença africana se demarcava pelo próprio sequestro de parte de sua população, via escravização.

Assim, com a frase "A minha ancestralidade africana está...", a professora foi a primeira a realizar a atividade posicionando-se em frente ao espelho. Após alguns instantes de reflexão silenciosa, começou a explicar como via a sua ancestralidade africana presente em si (na cor de sua pele, nos seus cabelos e olhos, nos seus familiares, entre outros aspectos). Em seguida, em um canto reservado da sala, solicitou que cada criança fizesse o mesmo e que, ao terminar, sentasse em silêncio para pensar sobre si e então desenhasse sua imagem, descrevendo em poucas palavras sobre sua ancestralidade africana.

Alguns cuidados foram tomados nessa atividade para não recair em lógicas distorcidas, como o mito da democracia racial ou a ideia esvaziada de igualdade, que atua muito mais para dirimir a ideia do racismo operante em nossa sociedade do que para combatê-lo. Assim, por mais que a todos tenha sido solicitada a busca de sua ancestralidade africana, foi demarcado coletivamente que os espaços de subalternidade ou de superioridade simbólica (com base na raça) estão para além de tais reconhecimentos e que, portanto, o racismo à brasileira é dilacerante para a população que acumula não só na alma ou na história a ancestralidade africana, mas também na cor da pele, na textura dos cabelos e nos traços físicos. Então, o exercício implicava um triplo movimento para algumas crianças: descobrir parte de sua história, perceber que desfruta de privilégios por não "estampar" tal história e recolocar essa história (que passa a ser, então, coletiva de um país) em posição tão privilegiada quanto outras, como a da sua ancestralidade europeia.

Entre as produções das crianças, algumas foram mais ou menos detalhadas, algumas com maior reconhecimento (independentemente da cor da pele) e outras com menor. É possível dividir as produções em duas categorias: aquelas que identificaram traços físicos presentes em si e/ou em seus familiares (por exemplo: "Minha ancestralidade africana é meus olhos, minha cor e minha, família", 4 "Minha ancestralidade africana está... Eu acho o meu cabelo e os olhos") e aquelas que associaram, além dos

A divulgação de todos os textos e ilustrações foi autorizada pelas crianças participantes. traços físicos, características culturais africanas às suas, como em: "Minha ancestralidade africana está... minhas roupas coloridas, meus colares, minha boca, meu nariz, minha mãe é negra. Sou morena". 


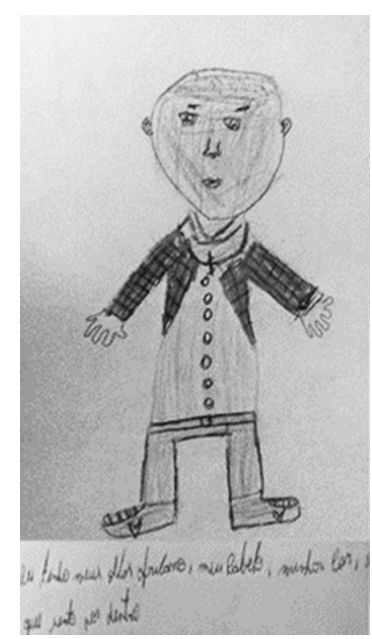

Figura 1: Autorretrato ${ }^{5}$

Fonte: Ilustração do aluno V.

Tais atividades, de modo geral, foram bastante significativas por produzirem, além de uma primeira ruptura epistemológica estimulada pelo conflito, um pequeno avanço na produção de novas interpretações acerca da cultura e da história africanas para aquelas turmas. E possível considerar, assim, que o "alfabetismo da diáspora" é uma prática necessária para solidificar a "retomada da iniciativa histórica". O alfabetismo da diáspora, proposto por Joice Elaine King, tem como objetivo recuperar a história e a cultura africanas como forma de resgatar a humanidade negra. Tal alfabetismo "possibilita que o povo negro re-possua 'nossa história', incluindo nossa identidade cultural como 'filhos e filhas da África'" (King, 1996, p. 82). Todo processo desenvolvido nesse princípio teórico se aproxima do objetivo de retomar a iniciativa histórica, meio pelo qual os povos colonizados retomarão para a "audácia histórica, a confiança em si" (Césaire, 2011, p. 269). Embora tal proposta seja inicialmente pensada para as sociedades africanas, Césaire reitera que todas aquelas que foram vítimas da colonização vivenciam características semelhantes e podem desenvolver caminhos para a retomada da iniciativa histórica:

Creio que as nossas culturas albergam dentro de si forças, vitalidade, capacidade de regeneração suficientes para se adaptarem às condições do mundo moderno, quando as condições objetivas que lhes impuseram forem modificadas; creio que elas poderão fornecer, para todos os problemas - sejam eles quais forem, políticos, sociais, econômicos, culturais -, soluções válidas e originais, válidas porque originais. (Césaire, 2011, p. 271-272, grifos do autor).

Considerando a pujante presença, influência e produção de conhecimentos originários da África, obviamente a iniciativa histórica no Brasil, responsável por produzir relativos impactos na representação hegemônica europeia e revisão de sua história, perpassa pelo reconhecimento

\footnotetext{
5 A legenda da Figura 1 diz: "eu tenho meus olhos africano, meu cabelo, minha cor e o que sinto por dentro".
} 
da sua estreita relação com aquele continente, assim como pela assunção de que a influência e a presença indígenas não se restringem meramente a algumas etnias e à herança vocabular e alimentar, e sim se relacionam diretamente com a forma como se construiu o Brasil, seu povo e sua cultura. Apenas quando essas histórias passarem a fazer parte do rol daquelas a serem contadas sobre este País, serão conquistadas autonomia e consciência humana condizentes com o que se classifica como "nação plural".

A educação formal é uma das principais instituições nesse processo por atuar cotidiana e diretamente na aquisição de conhecimentos. Se os conhecimentos por ela desenvolvidos e apresentados são "mono-históricos" e fundamentados sob a ótica do colonizador, inevitavelmente o processo de retomada da iniciativa histórica perde a validade. É preciso, portanto, descolonizar o currículo, os conhecimentos e as mentes.

No entanto, as práticas pedagógicas neste artigo relatadas produziram também rupturas negativas ou, pelo menos, expuseram feridas em falso processo de cicatrização. Apresentar tais situações é necessário também para ratificar que o processo de alfabetismo da diáspora é lento, gradativo e constituído de avanços e retrocessos. Houve certa dificuldade por parte de um grupo de estudantes na atividade que consistia em se olhar no espelho. Em especial, duas crianças negras, um menino e uma menina de turmas diferentes evitaram essa atividade. O menino, aqui apresentado com a inicial de seu nome, B, após a professora conversar sobre a importância daquela atividade para o coletivo da turma e sobretudo para negros e negras como ela, ainda com resistências (dizendo que não conseguia), posicionou-se em frente ao espelho, mas sem conseguir se olhar. Posicionada atrás dele, a professora fez um suave movimento de erguer seu queixo para que visse o ser humano refletido naquela imagem.

Enquanto a turma conversava, pintava ou desenhava suas ilustrações, não foi possível ouvir integralmente o diálogo de ambos, no qual a professora se referia à importância de sua história, de sua ancestralidade e de sua nobreza, que estava tanto externa como visivelmente expressa. Alguns minutos depois, ele conseguiu olhar para a imagem refletida no espelho e, também contendo as lágrimas tal como a professora, sorriu. Depois de permanecer mais alguns minutos sozinho se olhando, ele fez a atividade com a seguinte legenda: "Minha ancestralidade africana está no meu cabelo, no meu sangue porque minha mãe é negra e o pai da minha mãe também".

Já na outra turma, a aluna C demonstrou maior dificuldade e, apesar da insistência, dos pedidos e, embora utilizando os mesmos argumentos mencionados com o outro aluno, ela não conseguiu se olhar, dizendo que não gostava. Ainda assim, atendendo ao pedido de tentar desenvolver a atividade escrita, ela produziu seu desenho com a legenda: "Eu não sei o que tenho de Africano" (Figura 2). 


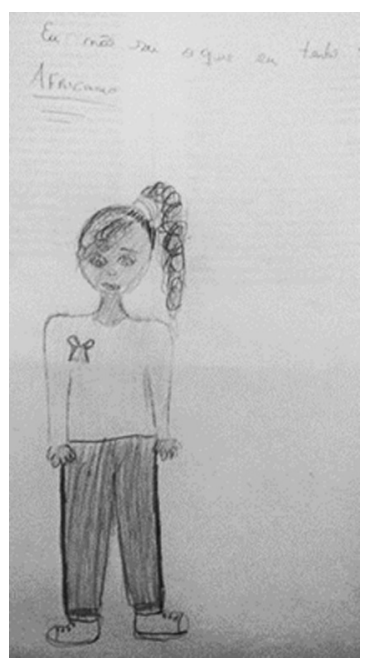

Figura 2 - Autorretrato

Fonte: Ilustração da aluna C.

Por meio das atividades, foi possível concluir que a maioria das crianças foi positivamente impactada, sobretudo por se tratar de um trabalho desenvolvido após muita reflexão, debates e mudanças de olhar. No entanto, apesar de se tratar de uma abordagem pedagógica atraente às turmas, considerando a afinidade e os laços estabelecidos pela convivência entre a professora e as crianças, esse sentimento não foi para todos. A baixa autoestima e a dor que marcavam aqueles pequenos corpos (e que foi bem demonstrada pela ilustração de C) eram maiores do que qualquer bom relacionamento que mantinham professora e aluna, incluindo a admiração, de modo generalizante, "dos cabelos da professora" ou o fato de a professora ser "legal". Não foram suficientes as cinco aulas por semana de convivência, durante quase um ano letivo, as trocas de experiências promovidas pelo princípio da dialogicidade, o posicionamento crítico e o enfrentamento das bases da gramática normativa, da literatura canônica e da produção textual convencional; da mesma forma, não foi suficiente a identificação pessoal com a professora (dadas as semelhanças entre seus pertencimentos étnico-raciais).

Assim, mais explicitamente é possível verificar a necessidade de incidências, de recorrências e, sobretudo, de incorporação curricular de práticas, conhecimentos, conteúdos e modos de se produzir saber com base em outras óticas que não somente as do colonizador. Tomando novamente as palavras de Césaire (2011), seu exemplo ilustra bem como e quando tal quadro negativo aqui exemplificado será superado: quando o povo conservar "a iniciativa histórica; dito de outro modo, quando este povo é livre, o que é incompatível com o colonialismo" (Césaire, 2011, p. 269). O problema é que o colonizador sabe disso e "é precisamente isto que, desde o primeiro dia, [...] tenta retirar, por todos os meios aos colonizados" (Césaire, 2011, p. 269).

Além disso, reitera-se o quanto ações coletivas impactam de modo mais incisivo em transformações sociais. Certamente as dificuldades se 
impuseram de tal forma por não se assemelhar a práticas adotadas pelo coletivo de docentes daquele ano letivo e dos anos anteriores. Isso retoma novamente aspectos sobre o racismo institucional, cuja força atua para minar iniciativas, ratificar o preconceito e inviabilizar ações ao impedir ou dificultar a promoção de condições adequadas para a formação continuada.

\section{Considerações finais}

Se concordarmos com a epígrafe deste artigo (Adichie, 2009), segundo a qual o problema com os estereótipos não é que eles sejam mentira, mas que são incompletos e, por isso, cristalizam uma e única história, ao ampliarmos essa reflexão para a educação brasileira, surge um grande desafio pela frente, pois ainda não nos libertamos das amarras da "obrigatoriedade" da lei para uma efetiva incorporação de uma consciência crítica. Estamos em estágio muito inicial de um alfabetismo da diáspora rumo à retomada da iniciativa histórica; enfrentamos cotidianamente a força do racismo institucional, que bate portas, ignora, omite, retira, restringe ou nega o acesso ao conhecimento de outras histórias.

Assim, propondo uma revisão dos marcos legais sobre a ERER e investigando mecanismos pelos quais o racismo institucional e o eurocentrismo operam como manifestações da colonialidade nos tempos atuais, este artigo também se propôs a contar uma história, ainda que repleta de estereótipos e alguns retrocessos, mas também com avanços e conquistas. Se o processo de alfabetismo rumo à leitura proficiente é gradativo e com oscilações, o alfabetismo da diáspora não tem sido diferente, sobretudo porque há, em nossos percursos de aprendizes, muitos obstáculos impostos pelo racismo. Entretanto, é possível almejar mudanças com a crença na efetividade do que Munanga (2008, p. 16) chama de "uma sociedade plural e de identidades múltiplas", com a reunião de esforços mobilizados pelas resistências no ambiente escolar, em que seja possível promover a iniciativa histórica e, assim, outras e tantas narrativas sejam possíveis para a educação brasileira.

\section{Referências bibliográficas}

ADICHIE, C. N. O perigo de uma história única. Tradução de Erika Rodrigues. out. 2009. Disponível em: <http://www.ted. com/talks/chimamanda_adichie_the_danger_of_a_single_story/ transcript?language $=\mathrm{pt}-\mathrm{br}>$. Palestra dada na Conferência TED Global. Acesso em: 10 maio 2017.

BRASIL. Lei $\mathrm{n}^{\circ}$ 10.639, de 9 de janeiro de 2003. Altera a Lei ${ }^{\circ}$ 9.394, de 20 de dezembro de 1996, que estabelece as diretrizes e bases da 
educação nacional, para incluir no currículo oficial da Rede de Ensino a obrigatoriedade da temática «História e Cultura Afro-Brasileira», e dá outras providências. Diário Oficial da União, Brasília, 10 jan. 2003. Seção 1, p. 1.

BRASIL. Lei $n^{\circ} 11.645$, de 10 de março de 2008. Altera a Lei ${ }^{\circ}$ 9.394, de 20 de dezembro de 1996, modificada pela Lei $\mathrm{n}^{\circ}$ 10.639, de 9 de janeiro de 2003, que estabelece as diretrizes e bases da educação nacional, para incluir no currículo oficial da rede de ensino a obrigatoriedade da temática «História e Cultura Afro-Brasileira e Indígena». Diário Oficial da União, Brasília, 11 mar. 2008. Seção 1, p. 1.

BRASIL. Conselho Nacional de Educação (CNE). Parecer CNE/CEB $\mathrm{n}^{\mathrm{o}}$ 13, de 10 de maio de 2012. Diretrizes Curriculares Nacionais para a Educação Escolar Indígena na Educação Básica. 2012. Disponível em: <http://portal.mec.gov.br/index.php?option=com_ docman\&view =download\&alias =10806-pceb013-12-pdf\&category_ slug $=$ maio-2012-pdf $\&$ Itemid $=30192>$.

BRASIL. Conselho Nacional de Educação (CNE). Parecer CNE/CP n ${ }^{\circ} 3$, de 10 de março de 2004. Diretrizes Curriculares Nacionais para a Educação das Relações Étnico-Raciais e para o Ensino de História e Cultura AfroBrasileira e Africana. 2004. Disponível em: <http://portal.mec.gov.br/ dmdocuments/cnecp_003.pdf $>$.

CAVALLEIRO, E. Do silêncio do lar ao silêncio escolar: racismo, preconceito e discriminação na educação infantil. 5. ed. São Paulo: Contexto, 2006.

CÉSAIRE, A. Cultura e colonização. In: SANCHES, M. R. As malhas que os impérios tecem: textos anticoloniais, contextos pós-coloniais. Lisboa: Ed. 70, 2011. p. 253-272.

DIAS, L. R. Cada um com seu jeito, cada jeito é de um! Campo Grande: Gráfica e Editora Alvorada, 2012.

FILICE, R. C. G. Raça e classe na gestão da educação básica brasileira. 2010. 342 f. Tese (Doutorado em Educação) - Faculdade de Educação, Universidade de Brasília, Brasília, 2010.

GOMES, N. L. Educação, raça e gênero: relações imersas na alteridade.

Cadernos Pagu, Campinas, n. 6-7, p. 67-82, 1996. 
GOMES, N. L. Relações étnico-raciais, educação e descolonização dos currículos. Currículo sem Fronteiras, v. 12, n. 1, p. 98-109, jan/abr. $2012 a$.

GOMES, N. L. As práticas pedagógicas com as relações étnico-raciais nas escolas públicas: desafios e perspectivas. In: GOMES, N. L. (Org.). Práticas pedagógicas de trabalho com relações étnico-raciais na escola na perspectiva da Lei $n^{o}$ 10.639/2003. Brasília: MEC; Unesco, 2012b. p. 19-33.

KING, J. E. A Passagem Média revisitada: a educação para a liberdade humana e a crítica epistemológica feita pelos estudos negros. In: SILVA, L. E. (Org.). Reestruturação curricular: novos mapas culturais, novas perspectivas educacionais. Porto Alegre: Sulina, 1996. p. 75-101.

LÓPEZ, L. C. O conceito de racismo institucional: aplicações no campo da saúde. Interface: Comunicação Saúde Educação, Botucatu, v. 16, n. 40, p. 121-34, jan/mar. 2012.

MALDONADO TORRES, N. Sobre la colonialidad del ser: contribuciones al desarrollo de un concepto. In: CASTRO-GÓMEZ, S.; GROSFOGUEL, R. (Orgs.). El giro decolonial: reflexiones para una diversidad epistémica más allá del capitalismo global. Bogotá: Universidad Javeriana-Instituto Pensar; Universidad Central-IESCO; Siglo del Hombre Editores, 2007. p. 127-167.

MUNANGA, K. Rediscutindo a mestiçagem no Brasil: identidade nacional versus identidade negra. 3. ed. Belo Horizonte: Autêntica, 2008.

QUIJANO, A. Colonialidade do poder, eurocentrismo e América Latina. In: LANDER, E. (Org.). A colonialidade do saber: eurocentrismo e ciências sociais: perspectivas latino-americanas. Buenos Aires: CLACSO, 2005. p. 227-278.

SANTOS, B. S. Para uma pedagogia do conflito. In: SILVA, L. E.; AZEVEDO, J. C.; SANTOS, E. S. Reestruturação curricular: novos mapas culturais, novas perspectivas educacionais. Porto Alegre: Sulina, 1996. p. 15-33.

SARZEDAS, L. P. M. Criança negra e educação: um estudo etnográfico na escola. 2007. 167f. Dissertação (Mestrado em Psicologia) - Faculdade de Ciências e Letras, Universidade Estadual Paulista, Assis, 2007. 
SILVA, T. T. Currículo e identidade social: territórios contestados.

In: SILVA, T. T. (Org.). Alienígenas na sala de aula. Petrópolis: Vozes,

1995. p. 190-207.

VAN DIJK, T. Discurso e poder. São Paulo: Contexto, 2008.

ZIVIANI, D. A cor das palavras: a alfabetização de crianças negras entre o estigma e a transformação. Belo Horizonte: Mazza, 2012.

Recebido em 25 de outubro de 2017.

Aprovado em 16 de março de 2018. 